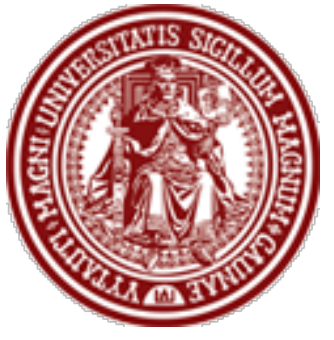

BALTIC JOURNAL OF LAW \& POLITICS

ISSN 2029-0454

https://content.sciendo.com/view/journals/bjlp/bjlpoverview.xml

\title{
RETRACTION REQUEST
}

As for Volume 12, Issue 2

1. Retraction of: Alexeiciuc, Sanda-Daniela, and Kirill N. Babichenko. 2013. The EU's Neighborhood Policy towards the Southern Caucasus: Searching for Commonality in a Patchy Scenario. Baltic Journal of Law \& Politics Volume 6, Number 2, pages 75-101.

2. Original DOI: $10.2478 / \mathrm{bjlp}-2013-0012$.

3. Description of the Retraction: it is retracted because of found plagiarism in the text.

4. Retraction DOI: $10.2478 / \mathrm{bj} \mid \mathrm{p}-2019-0017$.

Senior Editor-in-Chief

Tomas Berkmanas 